\title{
Hyperspectral Imaging from a Multipurpose Floating Platform to Estimate Chlorophyll- $a$ Concentrations in Irrigation Pond Water
}

\author{
Geonwoo Kim ${ }^{1}$, Insuck Baek ${ }^{1,2}$, Matthew D. Stocker ${ }^{1,2}$, Jaclyn E. Smith ${ }^{1,2}$, \\ Andrew L. Van Tassell ${ }^{3}$, Jianwei Qin ${ }^{1}$, Diane E. Chan ${ }^{1}$, Yakov Pachepsky ${ }^{1}$ and Moon S. Kim ${ }^{1, *}$ \\ 1 Environmental Microbial and Food Safety Laboratory, Agricultural Research Service, United States \\ Department of Agriculture, Beltsville, MD 20705, USA \\ 2 Oak Ridge Institute for Science and Education, 1299 Bethel Valley Rd, Oak Ridge, TN 37830, USA \\ 3 Department of Mechanical Engineering, Iowa State University, 2025 Black Engineering, Ames, IA 50011, USA \\ * Correspondence: Moon.Kim@usda.gov
}

Received: 4 June 2020; Accepted: 25 June 2020; Published: 27 June 2020

\begin{abstract}
This study provides detailed information about the use of a hyperspectral imaging system mounted on a motor-driven multipurpose floating platform (MFP) for water quality sensing and water sampling, including the spatial and spectral calibration for the camera, image acquisition and correction procedures. To evaluate chlorophyll- $a$ concentrations in an irrigation pond, visible/near-infrared hyperspectral images of the water were acquired as the MFP traveled to ten water sampling locations along the length of the pond, and dimensionality reduction with correlation analysis was performed to relate the image data to the measured chlorophyll- $a$ data. About 80,000 sample images were acquired by the line-scan method. Image processing was used to remove sun-glint areas present in the raw hyperspectral images before further analysis was conducted by principal component analysis (PCA) to extract three key wavelengths $(662 \mathrm{~nm}, 702 \mathrm{~nm}$, and $752 \mathrm{~nm})$ for detecting chlorophyll- $a$ in irrigation water. Spectral intensities at the key wavelengths were used as inputs to two near-infrared (NIR)-red models. The determination coefficients $\left(R^{2}\right)$ of the two models were found to be about 0.83 and 0.81 . The results show that hyperspectral imagery from low heights can provide valuable information about water quality in a fresh water source.
\end{abstract}

Keywords: Irrigation pond water; principal component analysis; chlorophyll- $a$ concentration; hyperspectral images; NIR-red model; remote sensing

\section{Introduction}

Irrigation water usage accounts for about $70 \%$ of all the world's freshwater withdrawals [1]. In the United States, irrigation withdrawals increased by two percent annually between 2010 and 2015, and accounted for approximately $42 \%$ of freshwater withdrawals in 2015 [2-4]. Hence, the need for safer and more efficient irrigation systems has drawn substantial attention recently and the number of related studies has rapidly increased [5-7]. In general, water quality is commonly evaluated by assessing chemical composition using in-situ sensor probes and/or laboratory-scale measurements in water samples collected on site. These conventional procedures are time-consuming and laborious, and have limited spatial coverage [8-10]. Microbial quality is also commonly used for evaluating water quality. Because irrigation water has the potential to be a vehicle for spreading serious human infections via agricultural produce, poor microbiological water quality can lead to severe hemorrhagic and gastrointestinal disease in humans [11-15]. Therefore, it is important that the microbial condition of irrigation water is regularly monitored. Among various microbial parameters, chlorophyll- $a$ 
concentration is one of the strongest indicators used to assess water quality, and quantifying the concentration of chlorophyll- $a$ is a standard method of monitoring the microbial conditions of a water body [16-18].

Analyzing major microbiological indicators for comparison with related standards and regulations is an important component of water quality assessment $[5,19,20]$. Although US standards for agricultural produce and microbiological rules for irrigation water were developed by the US Food and Drug Administration (FDA), assessing irrigation water quality remains difficult because the variability of the microbial quality across irrigation water sources can be high [15].

Visualizing the spatial patterns of microbiological parameters from data of in-situ sampling is difficult because the resolution of the spatial pattern map relies on the number of sampling locations used; the required number of samples can be prohibitively high [21]. Hyperspectral sensing for water quality can complement the conventional method with intensive spatial coverage and repetitive temporal coverage. Hyperspectral imaging technology has been used in agricultural, environmental, medical, military and other applications for over three decades. Hyperspectral imaging can efficiently and accurately estimate water resource parameters by analyzing spatial, spectral and temporal variations [10,22-25]. In particular, hyperspectral remote sensing for monitoring water quality has been developed with satellites and airborne platforms $[8,26,27]$. However, to the best of our knowledge, only a few hyperspectral studies for assessing irrigation pond quality have recently been conducted $[9,24,28,29]$.

The objective of this study was to perform a pilot study on mapping of water quality parameters in an irrigation pond. Hyperspectral imaging was performed with the camera located in close proximity over the water surface. To obtain microbial information and environmental covariates in the interior regions of irrigation ponds and reservoirs, the multipurpose floating platform (MFP) was designed and deployed to standardize the imaging conditions and to couple imaging with water sampling and testing with sensors. These tasks had been found very difficult to do in earlier studies that used traditional water sampling methods performed from kayaks. The MFP carried a hyperspectral imaging system, a water quality sensing device, and multi-tier water sampling module. The speed of the MFP was precisely controlled by a trolling motor, a global positioning system (GPS), and a sonar system, in order to match the sensing data with the hyperspectral images that were collected. All sensing data was stored in a control computer. The hyperspectral imaging and the chlorophyll- $a$ sensing of irrigation water were simultaneously conducted by the hyperspectral camera fixed on the MFP and a handheld water quality monitoring device. Before taking hyperspectral images, spectral and spatial calibrations were performed to assign wavelengths to the pixels of the spectral dimension and define the hyperspectral image resolution. The obtained hyperspectral images of irrigation water were subjected to image processing to remove sun-glint effects on the water surface. After image processing, principal component analysis (PCA) was conducted to extract key wavelengths within the chlorophyll- $a$ absorption bands of the NIR-red models which have been widely used for the chlorophyll- $a$ evaluation of water resources [30-33], and the correlations of the hyperspectral imaging data with chlorophyll- $a$ concentrations were obtained and analyzed.

\section{Materials and Methods}

\subsection{Irrigation Pond}

This study was conducted at an excavated irrigation pond located at the University of Maryland Wye Research Center (Queenstown, Maryland, USA) (Figure 1). This pond was selected because it is an actively used irrigation pond where previous studies were conducted to analyze E. coli concentration variability and relationships with environmental covariates [12,15,34]. The pond's average depth, total length, and area are approximately $2.7 \mathrm{~m}, 191 \mathrm{~m}$, and $447 \mathrm{~m}^{2}$, respectively. To minimize sun-glint effects, the irrigation water sampling and sensor measurements as well as the hyperspectral imaging were simultaneously conducted between 9:00 am and 11:00 am during the growing season of plants 
(July-August). Hyperspectral image samples were collected on 4 days, and the details of weather conditions on those days in Table 1.

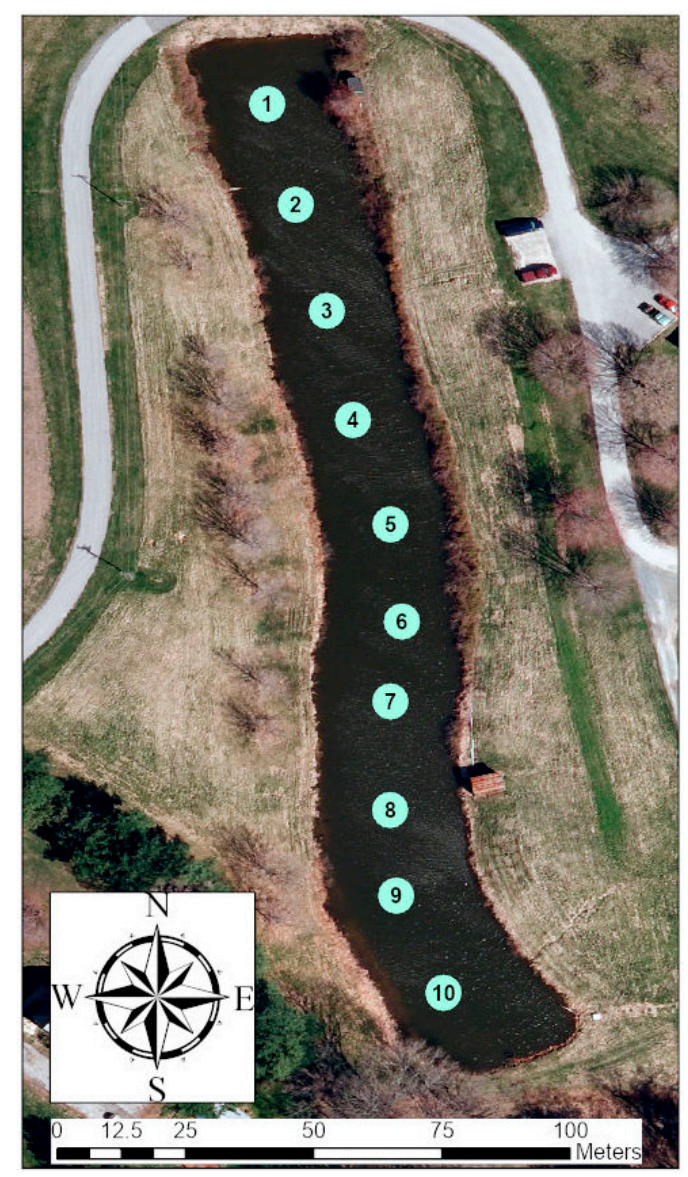

Figure 1. Irrigation pond at the Wye Research and Education Center of the University of Maryland $\left(38^{\circ} 54^{\prime} 59.4^{\prime \prime} \mathrm{N} 76^{\circ} 08^{\prime} 29.0^{\prime \prime} \mathrm{W}\right.$, Queens town, Maryland, US). Numbered water sampling locations are shown. (The image is from Google Maps [imagery (C2017 Google, map data (C2020 Google]).

Table 1. Weather conditions and water temperatures on data collection days.

\begin{tabular}{ccccc}
\hline & Time & Condition & $\begin{array}{c}\text { Water } \\
\text { Temperature }\left({ }^{\circ} \mathbf{C}\right)\end{array}$ & Wind Speed (m/s) \\
\hline 29 July 2019 & $09: 00-11: 00$ & Sunny & $27.5-28.3$ & $2.2-2.7$ \\
\hline 15 Aug 2019 & $09: 00-11: 00$ & Sunny & $26.9-27.2$ & $3.1-5.3$ \\
\hline 22 Aug 2019 & $09: 00-11: 00$ & Sunny & $28.5-29.8$ & $3.1-3.6$ \\
\hline 30 Aug 2019 & $09: 00-11: 00$ & Sunny & $28.2-30.6$ & $0-2.7$ \\
\hline
\end{tabular}

The water temperatures listed in Table 1 were measured by a water quality monitoring device (YSI Exo-2 Sonde, YSI Inc., Yellow Springs, USA). Sampling and imaging of pond water was conducted at the 10 locations shown in Figure 1. The 10 locations were geotagged so that measurements could be performed at the same locations across all sampling dates. Water samples were collected with a $500 \mathrm{~mL}$ bottle and were immediately placed on ice in enclosed dark storage. Chlorophyll- $a$ content of pond water was measured using the YSI-Exo-2. Detailed information about the pond, sampling, and sensing methodology can be found in our previous publications [12,34]. 


\subsection{MFP Design and Components}

Figure 2 shows the schematic diagram of the MFP and a photo of the MFP taken during field testing on the irrigation pond. The MFP consists of hulls, stainless steel plates, aluminum profiles, a laptop computer, two trolling motors (MINN KOTA, Pontoon 55, USA), two batteries (12 V, 100 Ah), a sonar including a GPS system (GPSMAP 547XS, GARMIN, USA), and an electronic control box. The handheld water quality monitoring device (YSI Exo-2 Sonde, YSI Inc., Yellow Springs, USA), a hyperspectral imaging camera (MicroHSI 410 SHARK, Corning Inc., USA), and the water sampling module (SPX-24, Amarine-Made, USA) were mounted on the MFP for this study. The electronic control box distributed the power voltage for the water sampling module, two trolling motors, the sonar, and the water quality monitoring device. The sonar scans the irrigation pond by using brightness scan (B-scan) mode for detailed representations of objects, structures, and fish in the water. Movement of the MFP can be controlled by the two trolling motors and its path history is stored by the GPS system. The MFP has a length of $3430 \mathrm{~mm}$, a width of $2160 \mathrm{~mm}$, a height of $980 \mathrm{~mm}$, and a maximum load capacity of approximately $1450 \mathrm{~kg}$.
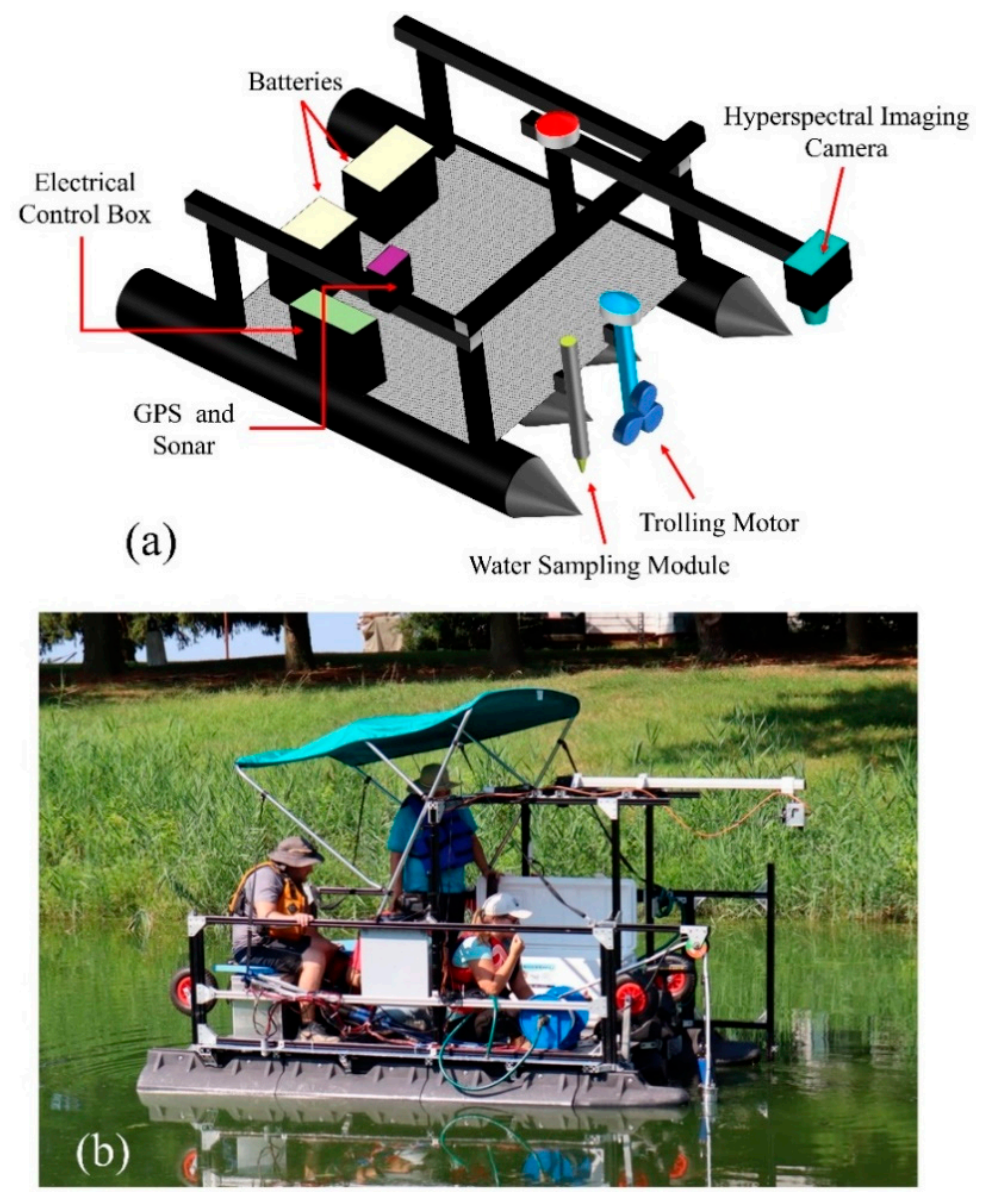

Figure 2. (a) Schematic diagram of the multipurpose floating platform (MFP) and (b) a field test photo.

Hyperspectral images of the water surface along with the water quality measurements were taken at the ten designated locations (Figure 1). The hyperspectral imaging system used in this study includes a push-broom line-scan sensor, a focal-plane array (FPA) detector, an imaging camera with 704 spatial $\times 155$ spectral pixel resolution, an $11.7 \mu \mathrm{m}$ slit, an objective lense (Xenoplan 1.9/35, Schneider Kreuznach, Germany), and a control computer with commercial control software for MicroHSI 410 SHARK. The FPA detector of the hyperspectral imaging sensor is a CCD/CMOS hybrid with 1408 spatial pixels. The spectral range spans the visible region and a portion of the near-infrared (NIR) 
region, from $400 \mathrm{~nm}$ to $1000 \mathrm{~nm}$ across 154 bands. The spectral bin size is $2 \mathrm{~nm}$ per pixel, and the maximum frame rate is $300 \mathrm{~Hz}$. The spectral and spatial information of the irrigation water was simultaneously acquired as the MFP moved in the water. The exposure time and frame rate were set to $8 \mathrm{~ms}$ and $120 \mathrm{~Hz}$ in this study.

\subsection{System Calibration}

Before taking hyperspectral images, spectral calibration to assign wavelengths to the pixels of the spectral dimension was performed for the hyperspectral imaging system. The calibration used pencil-style Ar, $\mathrm{Hg}-\mathrm{Ne}, \mathrm{Kr}$, and Ne lamps (Oriel Instruments, CA, USA), which have been widely used for spectral calibration in the environmental and agricultural fields [35-37]. From the excitation gases and metal vapors contained within, the lamps generate spectral peaks at known wavelengths that can be detected by the imaging sensor of the hyperspectral camera. In a darkened environment, the spectral calibration lamps were placed on a black surface approximately $600 \times 500 \mathrm{~mm}$ in size at the distance of $250 \mathrm{~mm}$ under the hyperspectral camera. Figure 3 shows the spectral calibration results for the hyperspectral imaging system used in this study.

(a)
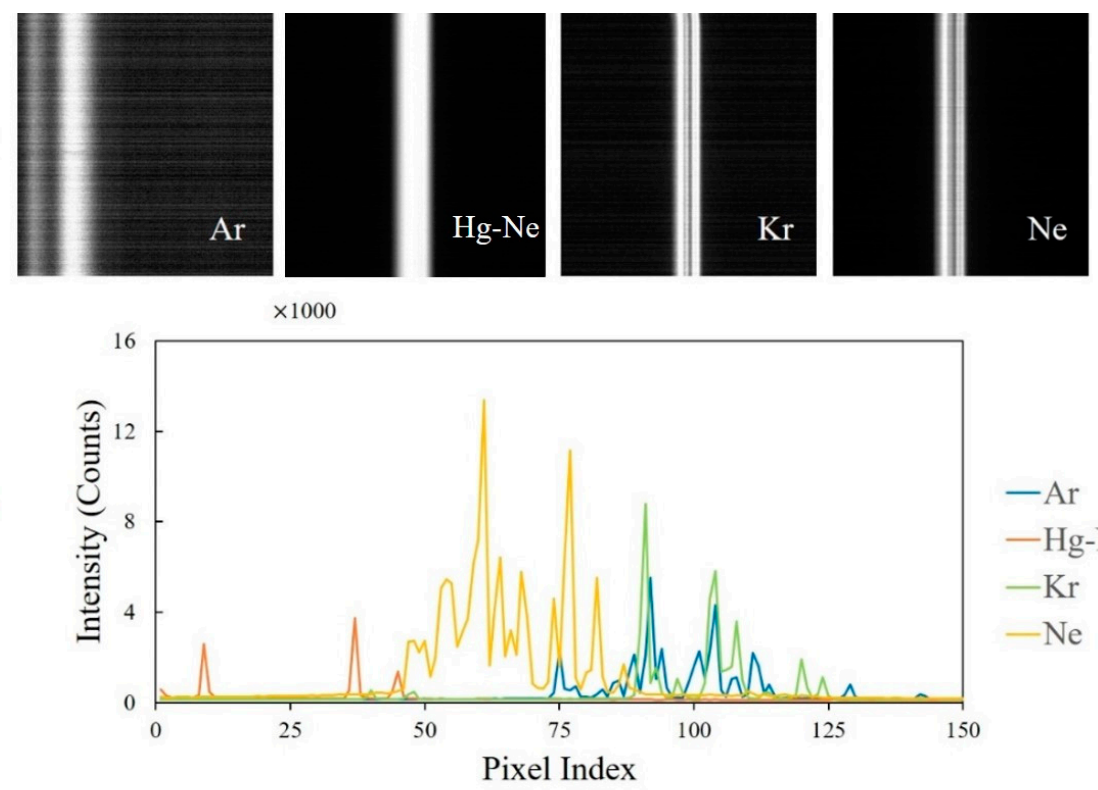

$$
-\mathrm{Ar}
$$

(b)

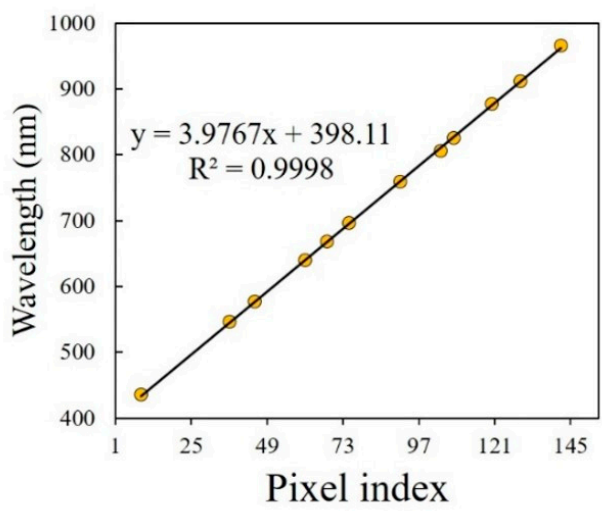

Figure 3. Spectral calibration of the MFP hyperspectral imaging system: (a) single-band example images from the hyperspectral images of $\mathrm{Ar}, \mathrm{Hg}-\mathrm{Ne}, \mathrm{Kr}$, and $\mathrm{Ne}$ lamps, (b) spectral profiles of each lamp, and (c) a linear regression model, where $y$ is wavelength and $x$ is pixel index.

Figure 3a shows a single-waveband image from the hyperspectral image for each of the Ar, $\mathrm{Hg}-\mathrm{Ne}, \mathrm{Kr}$, and Ne calibration lamps. The spectral profiles shown in Figure $3 \mathrm{~b}$ were extracted from 
the horizontal axis of the hyperspectral images and provide the horizontal (spectral) x-pixel at the vertical (spatial) y-pixel in the region of 400-1000 nm. From the spectral profiles, the relationship between pixel positions and corresponding wavelengths was derived by a linear regression function as shown in Figure 3c. The $\mathrm{R}^{2}$ values in the linear fit is 0.999 . The spatial calibration is used to determine the hyperspectral image resolution, and to adjust the field of view and spatial detection limit. For a line-scan imaging system, the spatial resolution depends on the step distance of the specimen movement. Figure 4 shows the hyperspectral image of a white paper target printed with parallel lines spaced $2 \mathrm{~mm}$ apart, which was used for spatial calibration.

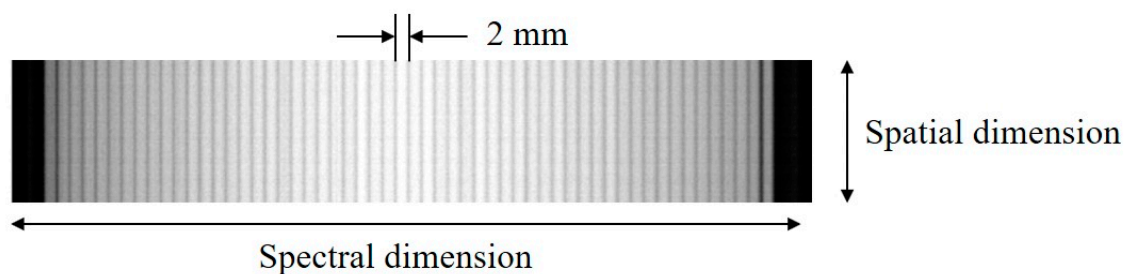

Figure 4. Spatial calibration for the MFP hyperspectral imaging system.

The hyperspectral image was taken outdoors on a sunny day, with $35 \mathrm{~mm}$ focal length, $1400 \mathrm{~mm}$ working distance, $11.3 \mathrm{~mm}$ spatial dimension of CCD, and 1408 spatial pixels of the CCD. The field of view (FOV) and spatial resolution of the hyperspectral imaging system are $452 \mathrm{~mm}$ and $0.32 \mathrm{~mm} / \mathrm{pixel}$, respectively. For detailed description of the calculations for the FOV and spatial resolution, readers are referred to Qin et al. [36].

\subsection{Hyperspectral Image Acquisition}

While the MFP moved in the pond at the speed of about $0.2 \mathrm{~m} / \mathrm{sec}$, spectral and spatial information of the imaged water surface were simultaneously acquired by the hyperspectral camera mounted on the MFP. The exposure time and frame rate were set to $8 \mathrm{~ms}$ and $120 \mathrm{~Hz}$, respectively. The hyperspectral images used in this study consisted of about 80,000 lines in total over 4 days of data collection using all ten locations on each day. When passing each location, the water monitoring device, GPS (including time information), and the hyperspectral camera were simultaneously activated, and data recorded. Thus, we could obtain the hyperspectral images with their location information. About 2000 lines were taken during a single pass at each of the ten locations marked in Figure 1. The total path length, including all ten locations shown in Figure 1, was about 191 m, which is, relatively, a much shorter length than typical geographical data for hyperspectral sensing. Each data collection day was very clear and sunny. There were no obstructions on the water surface and it took about $15 \mathrm{~min}$ for imaging the total length. The velocity of the MFP was precisely controlled by the trolling motor and GPS system, and the sonar system was used to monitor for potential underwater obstructions. Therefore, there was no critical variability regarding sensing location. Images of the white alumina and black reference boards were taken every 5 min after taking hyperspectral sample images.

The raw hyperspectral images of irrigation water were subjected to image processing to remove sun-glint effects. These effects include broad high-intensity spectral signals resulting from direct (specular) light reflection off the water surface at the same angle as that viewed by the CCD sensor [17,27]. The actual spectral response of the hyperspectral images were extracted by first performing a correction to relative reflectance for the sample images by using the white and black reference board images, and then, for all remaining image pixels of abnormally high intensity (sun-glint pixels), reassigning their values to zero (black pixel). The darkened sun-glint image pixels subsequently were omitted from further image processing and analysis. The corrected image was acquired using the following equation [36-38].

$$
I_{R}=\frac{I_{r}-I_{b}}{I_{w}-I_{b}}
$$


where $I_{R}$ is the relative reflectance image; and $I_{r}, I_{w}$, and $I_{b}$ are the hyperspectral images of the sample, the white alumina reference board, and the black reference board, respectively. Mean values of the white and dark reference spectra were used in Equation (1) for image correction. Figure 5 shows a comparison of an image from before and after image processing.

(a)

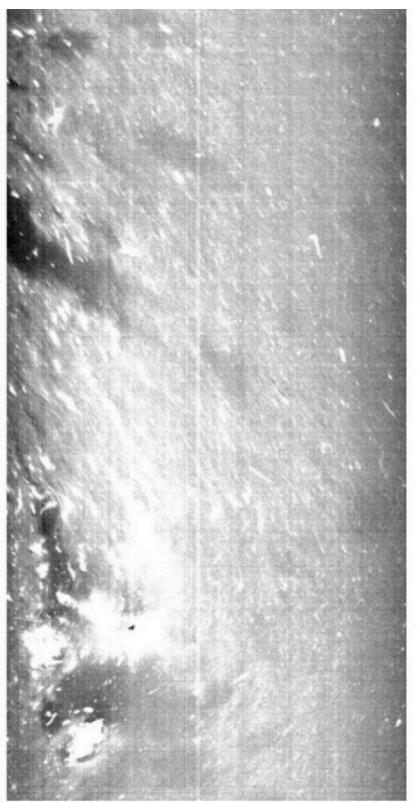

(b)

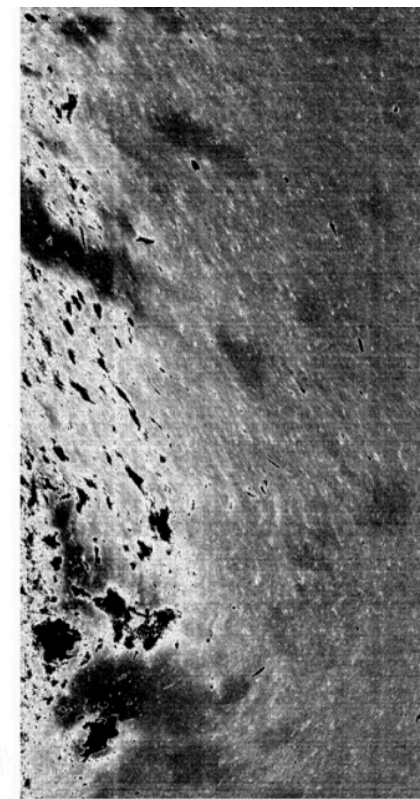

Figure 5. Single-wavelength $670 \mathrm{~nm}$ image of pond water surface: (a) before image processing and (b) after image processing.

Figure 5a presents an example $670 \mathrm{~nm}$ single-wavelength image that shows sun-glint effects that need to be removed by processing. In Figure $5 b$, the sun-glint parts are masked in black (pixel intensities set to zero). The process of calculating relative reflectance can also enhance some spectral differences between the typical raw reflective spectra of water resources $[16,18,30,33]$ as shown in Figure $6 \mathrm{a}$ and the corresponding preprocessed image spectra in Figure $6 \mathrm{~b}$. Sample images acquired by the hyperspectral imaging system on the MFP were stored as 12-bit bitmap images and analyzed using Matlab (MathWorks, USA), and Excel (Microsoft, USA).
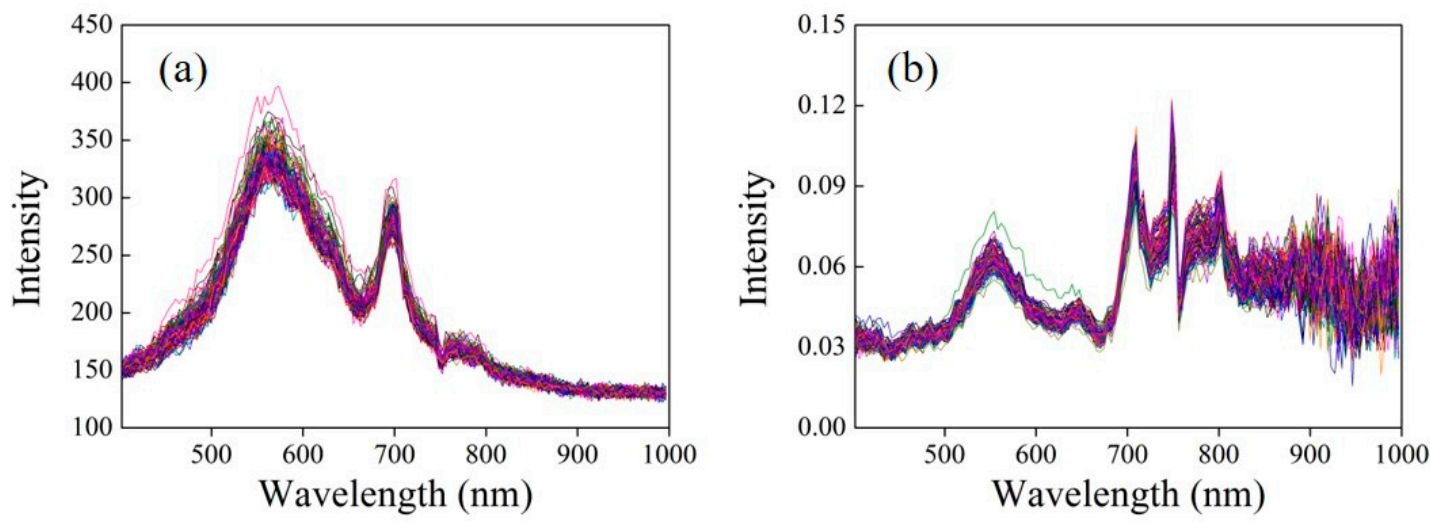

Figure 6. Example of the reflectance spectra: (a) before and (b) after image processing.

\subsection{Key Wavelength Selection and NIR-red Models}

The search for key wavelengths to correlate reflectance to chlorophyll- $a$ in irrigation water was defined as a search within the spectral reflectance region acquired in the sample images. In the spectra 
shown in Figure 6, absorption around the $670 \mathrm{~nm}$ region is mainly due to the chlorophyll- $a$ in water, occurring within the typical chlorophyll- $a$ detection region $[8,27,37]$. To select key wavelengths from the sample image spectra, the PCA was performed [33,39-41]. The selected key wavelengths were to be used for the NIR-red model $[31,32]$ and the model outcome was to be compared with the measured chlorophyll- $a$ concentrations $(\mu \mathrm{g} / \mathrm{L})$ of the irrigation pond water for verifying the relationship between the measured concentration data and the MFP hyperspectral images.

Three spectral ranges $\left(\lambda_{1}=660 \sim 670 \mathrm{~nm}, \lambda_{2}=700 \sim 730 \mathrm{~nm}\right.$ and $\left.\lambda_{3}=740 \sim 760 \mathrm{~nm}\right)$ were used for selecting key wavelengths [30,31], because these regions have low absorption capacity for the suspended solids and colored dissolved organic matter [31,32,42,43]. After performing the PCA, reflectance intensities at the key wavelengths selected from the three spectral ranges were used as inputs for the NIR-red models that use reflectance in the red and the near-infrared regions [31,32], and determination coefficients $\left(\mathrm{R}^{2}\right)$ values were obtained between the models and the measured chlorophyll- $a$ data. Equations (2) and (3) are the NIR-red models that were used.

$$
\begin{gathered}
\text { Chlorophyll - } a \propto\left(\mathrm{R}_{\lambda_{1}}^{-1}-\mathrm{R}_{\lambda_{2}}^{-1}\right) \times \mathrm{R}_{\lambda_{3}} \\
\text { Chlorophyll }-a \propto \mathrm{R}_{\lambda_{1}}^{-1} \times \mathrm{R}_{\lambda_{2}}
\end{gathered}
$$

These models have been developed and applied to many purposes related to chlorophyll- $a$ detection and correlation in turbid water [30-33]. Figure 7 shows the workflow used for analyzing the hyperspectral images.

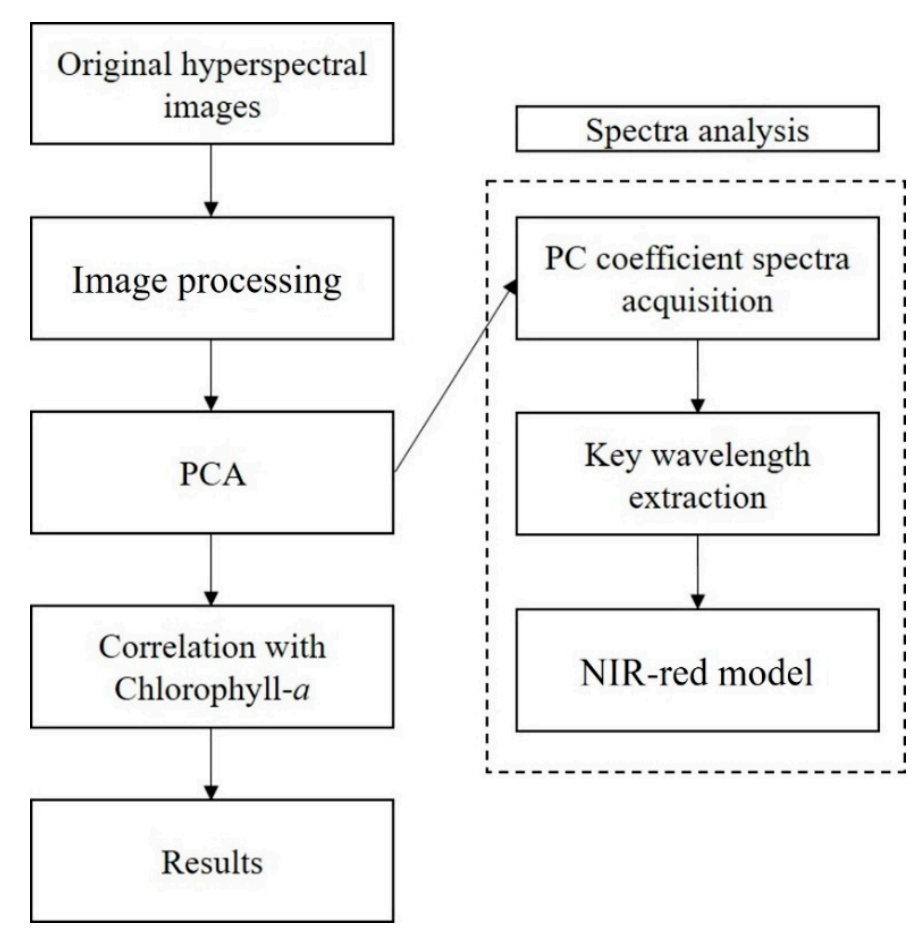

Figure 7. Flow chart of hyperspectral image analysis for chlorophyll- $a$ correlation.

\section{Results and Discussion}

Figure 8 shows the percentage of variance explained in the sample images by each principal component (PC) and the cumulative variance accounted for with each additional PC. 


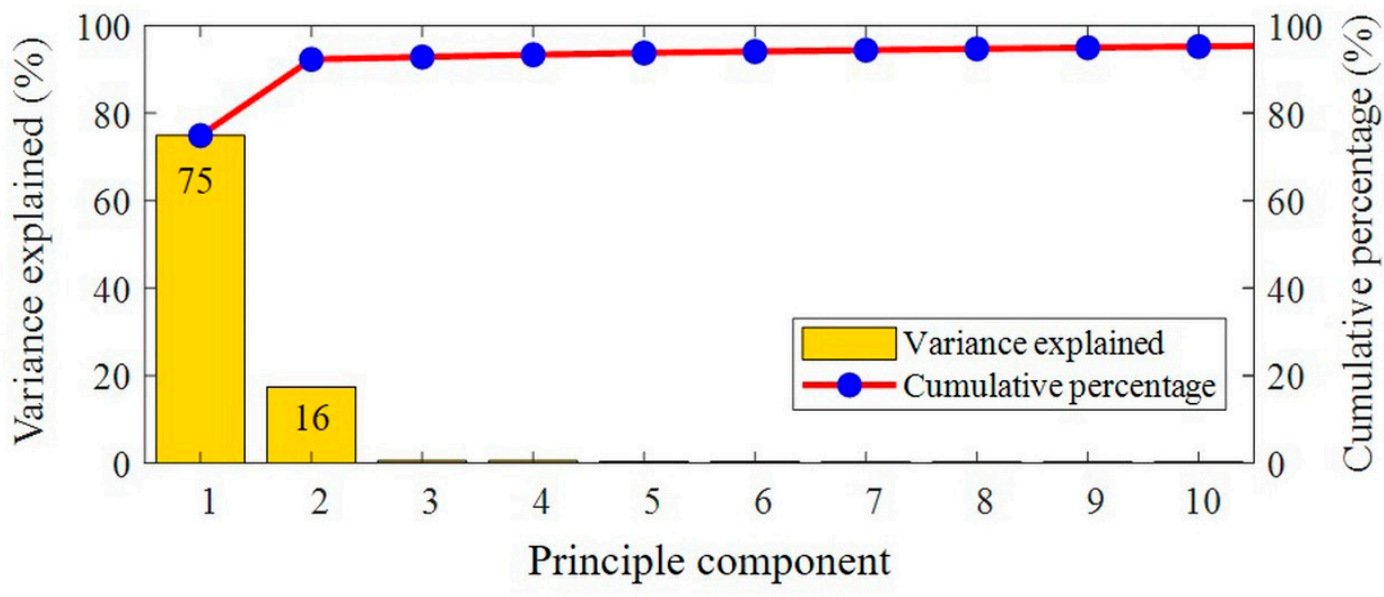

Figure 8. Principal component (PC) variance plot of 10,000 line sample images (bars) and cumulative explained variance (line).

For the PCA analysis, about 250 lines were selected for each single pass of each of the ten locations, for a total of 10,000 lines (four days, ten passes on each day). A set of 10,000 lines of preprocessed images was used for PCA. Although 154 PCs were created, Figure 8 only shows data for PCs 1 to 10 because the rest of PCs explain less than 1\% of the hyperspectral images. PC 1 through PC 4 accounted for approximately $93 \%$ of the data variation, and visual evaluation suggested that images beyond PC 3 contained no useful attributes. About $93 \%$ of the variability in images were explained by PCs 1 through 3 , and PC 1 alone accounts for $75 \%$. These characteristics are also found in their PC images as shown in Figure 9.
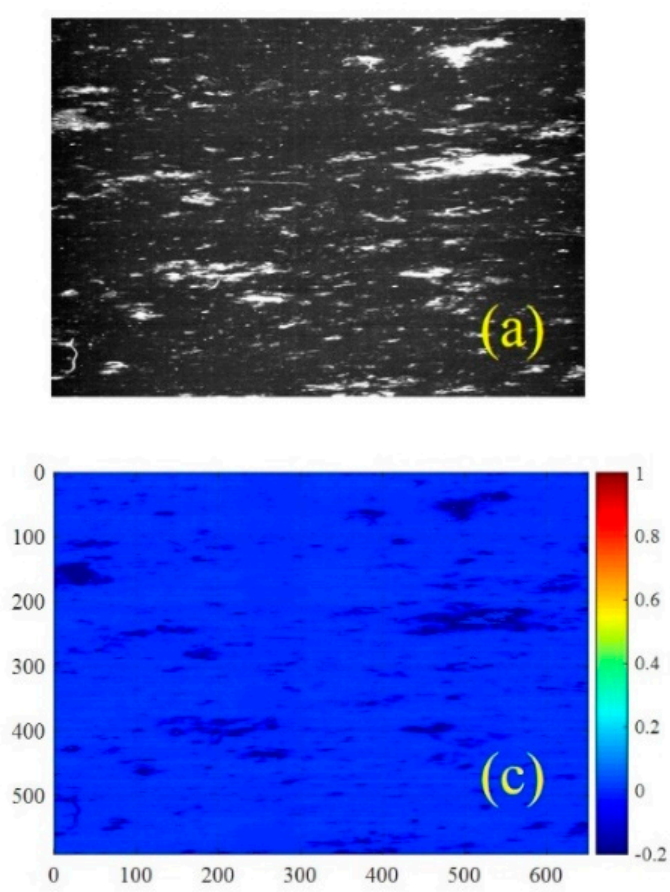
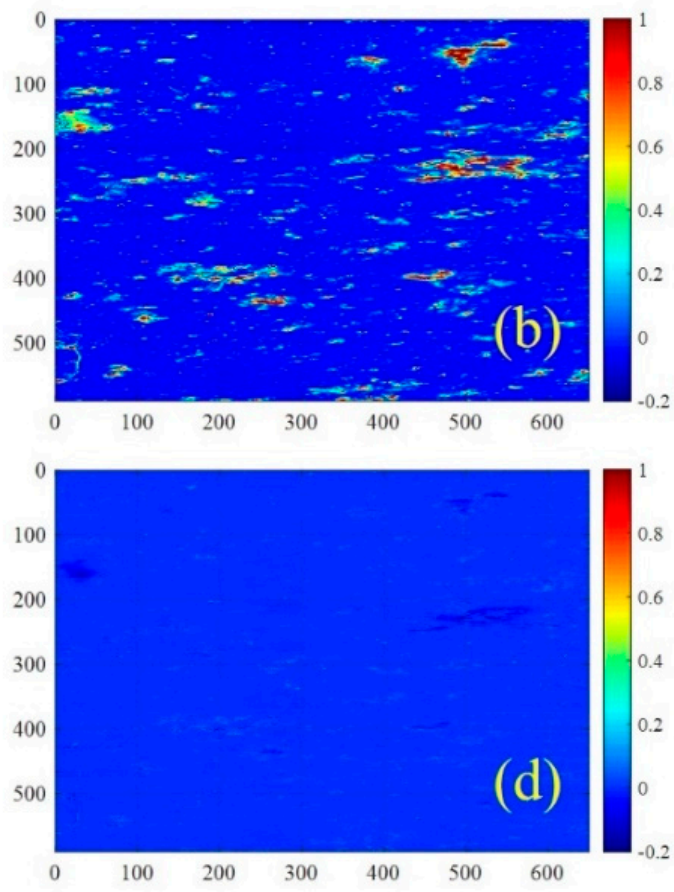

Figure 9. (a) Raw sample image at $670 \mathrm{~nm}$, (b) PC 1 image, (c) PC 2 image, and (d) PC 3 image.

In Figure 9, a raw sample image and its first three PC images are presented. The single-waveband image shown is at $670 \mathrm{~nm}$ and is a part of Figure 5a, which does not include any image processing. In Figure 9b, as expected, PC 1 can describe nearly all the major characteristics of the sample image, while in Figure 9c,d PC 2 and PC 3 describe very little of the characteristics of the sample image. 
The PC coefficient spectra of the three PCs are shown in Figure 10. To select key wavelengths from the PC 1, PC 2, and PC 3 images, the coefficients of each PC were obtained according to wavelength and examined within the three spectral ranges $\left(\lambda_{1}, \lambda_{2}\right.$, and $\left.\lambda_{3}\right)$ for correlation to chlorophyll- $a$.

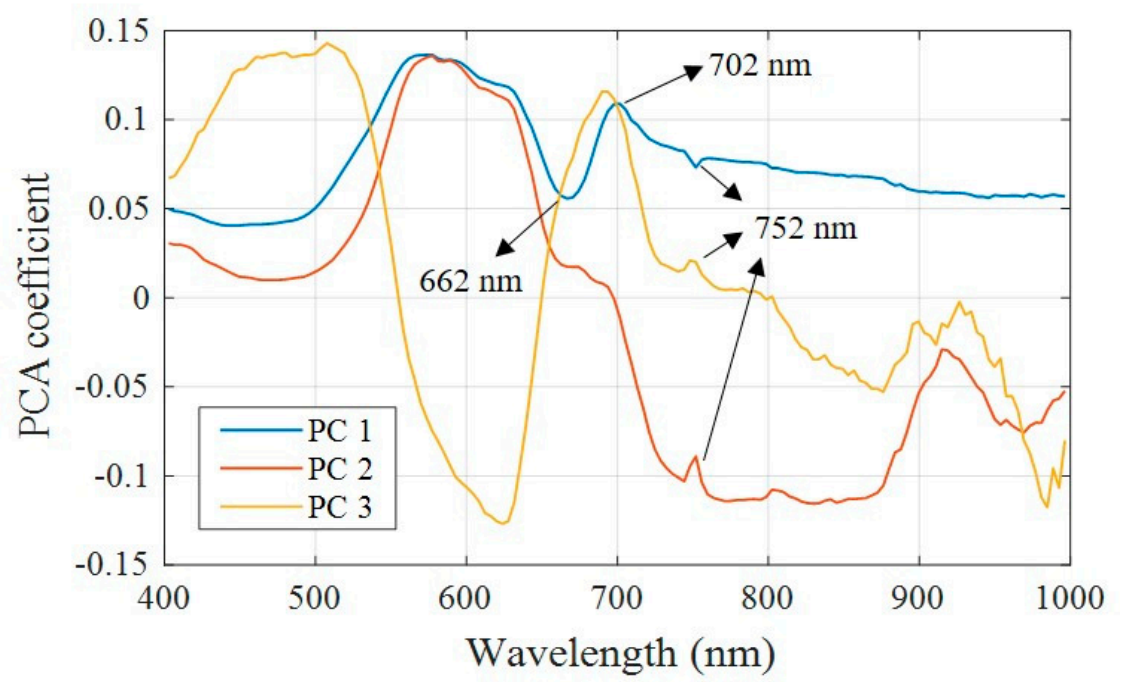

Figure 10. PC coefficient spectra of the hyperspectral image samples (10,000 lines) and the key wavelengths for detecting chlorophyll- $a$.

In Figure 10, the peaks and valleys within the spectral ranges $\left(\lambda_{1}, \lambda_{2}\right.$, and $\left.\lambda_{3}\right)$ indicate the dominant wavelengths, where $662 \mathrm{~nm}$ for PC 1, $702 \mathrm{~nm}$ for PC 2, and $752 \mathrm{~nm}$ for PC 3 were observed as local minima/maxima features. The PC 1 wavelength appeared to be similar with the typical absorption region (from $640 \mathrm{~nm}$ to $680 \mathrm{~nm}$ ) of chlorophyll- $a$. This indicates that the reflectance of chlorophyll- $a$ significantly influences the construction of the PC 1 image and could be used as a combination of spectral bands for the chlorophyll- $a$ evaluation of irrigation water [18,44]. The PC 2 and PC 3 coefficients reveal positive values in the NIR region, which can be used in the NIR-red models. In this study, PCA results shows the dominant peaks and valleys within the selected spectral ranges. Based on these facts, the result is statistically significant. When more robust and sophisticated models are needed rather than the simple correlation model investigated in this study, then we can use feature selection methods to find the key wavelengths, such as chemometrics models. From the above analysis, the PC 1 image appeared to provide the best performance for evaluating chlorophyll- $a$ concentration in irrigation water. Therefore, the three key wavelengths were extracted at peak and valley points within the optimal spectral ranges $\left(\lambda_{1}, \lambda_{2}\right.$ and $\left.\lambda_{3}\right)$ for chlorophyll- $a$ correlation, selected at $\lambda_{1}=662 \mathrm{~nm}$, $\lambda_{2}=702 \mathrm{~nm}$ and $\lambda_{3}=752 \mathrm{~nm}$. The selected key wavelength is summarized in Table 2.

Table 2. Selected key wavelength for assessing chlorophyll- $a$ concentration of the irrigation pond.

\begin{tabular}{cc}
\hline Spectral Range (nm) & Selected Key Wavelength (nm) \\
\hline$\lambda_{1}(660 \sim 670)$ & 662 \\
\hline$\lambda_{2}(700 \sim 730)$ & 702 \\
\hline$\lambda_{3}(740 \sim 760)$ & 752 \\
\hline
\end{tabular}

In addition, the coefficient spectra of PC 1 has all three key wavelengths for the two NIR-red models because of its high coefficient and $\lambda_{3}$ was universally included in PC1, PC2 and PC3. The selected key wavelengths were used for the NIR-red models and the outcomes were compared with the measured chlorophyll- $a$ concentration $(\mu \mathrm{g} / \mathrm{L})$ in the pond. A total of 108 consecutive measurements for chlorophyll- $a$ concentration were acquired along with about 80,000 lines of hyperspectral image data while the MFP traveled to the sampling locations in the irrigation pond (Figure 1). About 740 image 
lines are compared with each individual single chlorophyll- $a$ concentration measurement. A total of 108 measurements of chlorophyll- $a$ data were compared with the NIR-red model results for the mean spectra. Figure 11 shows the result of two NIR-red models (Equations (2) and (3)) versus measured chlorophyll- $a$ concentrations.
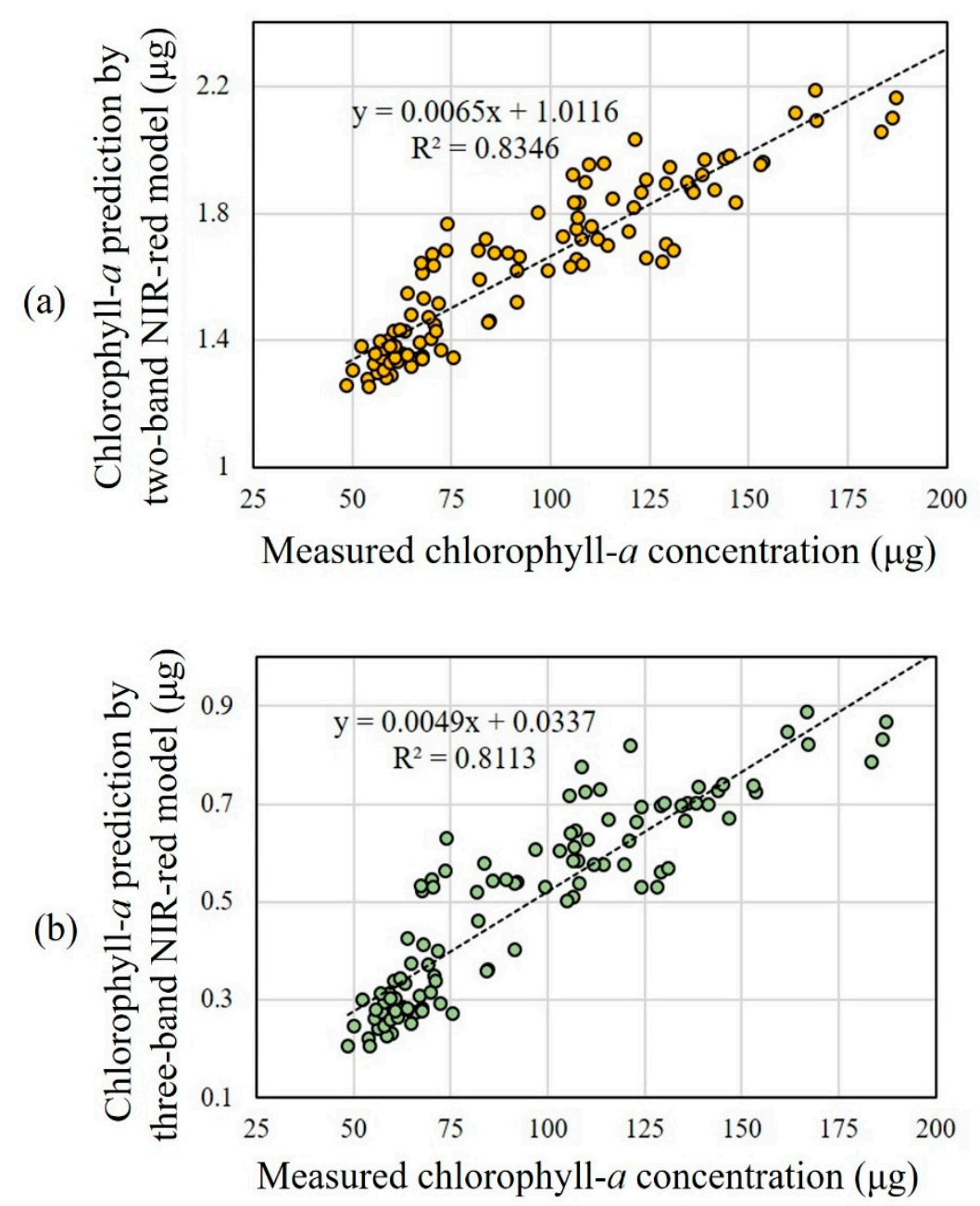

Figure 11. Plots of NIR-red models versus measured chlorophyll- $a$ concentrations: (a) two-band NIR-red model and (b) three-band NIR-red model.

Figure 11 shows the relationship between the NIR-red model predictions using the selected key wavelengths and the measured chlorophyll- $a$ concentrations. The two models show very similar results. The determination coefficients $\left(\mathrm{R}^{2}\right)$ of both the two-band and three-band models are above 0.8 with the removal of two outliers beyond $\pm 2 \sigma$. The irrigation pond imaging presented many variables that can affect the model outcome from the MFP-mounted hyperspectral imaging system such as floating matter, the interval of white and dark current calibration, and the chlorophyll- $a$ sensing interval. Because the hyperspectral imaging was performed from a low height, floating and subsurface objects such as insects, leaves, branches, and various aquatic organisms were included in the images. These objects were neglected in this study because we focused on assessing the chlorophyll- $a$ concentration in the water for correlation to the spectral image data. The detection or classification of objects in the water is a separate research topic requiring different methods of approach [45]. The intensity of sunlight and the movement of clouds affected the brightness of the obtained images. To prevent this, increasing the frequency of the calibration images would be an effective way to improve correlation accuracy. The chlorophyll- $a$ sensing interval was the most important factor influencing correlation accuracy 
because the resolution of the hyperspectral images was closely related to the number of lines. As noted above, the number of measured chlorophyll- $a$ concentration data and hyperspectral line images were not matched: compared to the number of hyperspectral images per location (about 740 lines), the number of chlorophyll- $a$ concentration measurements per location (about 108) was relatively small. The numbers of the chlorophyll- $a$ sample measurements and the line scan images were about 108 and 80,000 , respectively. Therefore, one sample measurement was compared with 740 lines. If the interval of chlorophyll- $a$ measurements is increased, the accuracy (resolution) of the model will be increased. In addition, the chlorophyll- $a$ data includes the real-time information and the time data is linked with the laptop computer which controls the hyperspectral camera. Then, we could match the measured chlorophyll- $a$ data with the hyperspectral information. This illustrates the higher data resolution that may be achieved by processing hyperspectral images of irrigation pond water compared to data point sensing. In considering other hyperspectral studies for water quality, this imaging method using the MFP may be applicable for assessing other major environmental parameters of irrigation ponds in addition to chlorophyll- $a$ concentration, such as suspended solids, colored dissolved organic matter, bacteria, nutrient concentrations, turbidity, and so on $[8,10,16-18,23,33,46,47]$. Consequently, the imaging from the MFP demonstrated the capability of building a spatial map of chlorophyll- $a$ concentration in the irrigation pond using the image processing and PCA method. Based on a review of other related articles, the chlorophyll- $a$ concentration of surface water can be also visualized by developing other regression models with inputs extracted from hyperspectral images $[8,10,40,46,47]$. This opens a promising research avenue to explore.

\section{Conclusions}

In this study, a line-scan hyperspectral imaging system for use on a multipurpose floating platform for assessing irrigation pond quality was introduced for obtaining the detailed spatial information of major environmental parameters. We studied the relationship between hyperspectral image data of the water acquired by the platform-mounted imaging system and data from irrigation water sampling. The detailed system specifications, image processing procedures, and correlation of hyperspectral images with chlorophyll- $a$-one of the most important environmental parameters for assessing water quality-were presented and analyzed. For verifying the usability of the designed hyperspectral imaging system, the correlation study was performed and led to a meaningful outcome. Based on the above simple field test and correlation result, the developed MFP-based methodology has potential for use as a rapid and precise method for evaluating irrigation water quality. In addition, fast-growing attention for irrigation water quality and the need for safe agricultural produce will also facilitate the development of various kinds hyperspectral imaging systems complementing and improving upon the one presented in this study.

Author Contributions: Conceptualization, M.S.K. and Y.P.; Methodology, M.S.K., G.K., and I.B.; Software, G.K., I.B., J.Q., and A.L.V.T.; Validation, G.K. and I.B.; Formal Analysis, G.K., I.B., D.E.C. and A.L.V.T.; Investigation, G.K. and I.B.; Resources, G.K., I.B., M.D.S., and J.E.S.; Data Curation, G.K.; Writing-Original Draft Preparation, G.K.; Writing-Review \& Editing, G.K., Y.P., D.E.C., M.D.S., and M.S.K.; Visualization, G.K., I.B., and A.L.V.T.; Supervision, M.S.K. and Y.P.; Project Administration, M.S.K. and Y.P.; Funding Acquisition, M.S.K. All authors have read and agreed to the published version of the manuscript.

Funding: This research was funded by USDA ARS Food Safety National Program projects, grant number 8042-42000-020-00D and 8042-12630-011-00D.

Conflicts of Interest: The authors declare no conflict of interest.

\section{References}

1. Irrigation Water Use. Available online: https://www.usgs.gov/special-topic/water-science-school/science/ irrigation-water-use?qt-science_center_objects=0\#qt-science_center_objects (accessed on 20 June 2020).

2. Dieter, C.A.; Maupin, M.A.; Caldwell, R.R.; Harris, M.A.; Ivahnenko, T.I.; Lovelace, J.K.; Barber, N.L.; Linsey, K.S. Estimated Use of Water in the United States in 2015; U.S. Geological Survey: Reston, VA, USA, 2018. 
3. Barber, N.L. Summary of estimated Water Use in the United States in 2005: U.S. Geological Survey Fact Sheet 2009-3098; U.S. Geological Survey: Reston, VA, USA, 2018.

4. Ouyang, Y.; Feng, G.; Read, J.J.; Leininger, T.D.; Jenkins, J.N. Estimating the ratio of pond size to irrigated soybean land in Mississippi: A case study. Water Sci. Technol. Water Supply 2016, 16, 1639-1647. [CrossRef]

5. Pettygrove, G.S.; Dennis, W.W.; Robert, S.A. Irrigation Water Quality Criteria. Irrig. Reclaimed Munic. Wastewater-A Guid. Man. 2019, 3-1-3-35. [CrossRef]

6. Mandal, S.K.; Dutta, S.K.; Pramanik, S.; Kole, R.K. Assessment of river water quality for agricultural irrigation. Int. J. Environ. Sci. Technol. 2019, 16, 451-462. [CrossRef]

7. Kavurmaci, M.; Apaydin, A. Assessment of irrigation water quality by a Geographic Information System-Multicriteria Decision Analysis-based model: A case study from Ankara, Turkey. Water Environ. Res. 2019, 1-13. [CrossRef]

8. Olmanson, L.G.; Brezonik, P.L.; Bauer, M.E. Airborne hyperspectral remote sensing to assess spatial distribution of water quality characteristics in large rivers: The Mississippi River and its tributaries in Minnesota. Remote Sens. Environ. 2013, 130, 254-265. [CrossRef]

9. Zovko, M.; Žibrat, U.; Knapič, M.; Bubalo, M.; Romić, M.; Romić, D. Hyperspectral imagery as a supporting tool in precision irrigation of karst landscapes. Adv. Anim. Biosci. 2017, 8, 578-582. [CrossRef]

10. Brando, V.E.; Dekker, A.G. Satellite hyperspectral remote sensing for estimating estuarine and coastal water quality. IEEE Trans. Geosci. Remote Sens. 2003, 41, 1378-1387. [CrossRef]

11. Rai, P.K.; Tripathi, B.D. Microbial contamination in vegetables due to irrigation with partially treated municipal wastewater in a tropical city. Int. J. Environ. Health Res. 2007, 17, 389-395. [CrossRef]

12. Stocker, M.D.; Smith, J.E.; Hernandez, C.; Macarisin, D.; Pachepsky, Y. Seasonality of E. coli and Enterococci Concentrations in Creek Water, Sediment, and Periphyton. Water Air Soil Pollut. 2019, 230, 1-12. [CrossRef]

13. Allende, A.; Monaghan, J. Irrigation water quality for leafy crops: A perspective of risks and potential solutions. Int. J. Environ. Res. Public Health 2015, 12, 7457-7477. [CrossRef]

14. Islam, M.; Doyle, M.P.; Phatak, S.C.; Millner, P.; Jiang, X. Survival of Escherichia coli O157:H7 in soil and on carrots and onions grown in fields treated with contaminated manure composts or irrigation water. Food Microbiol. 2005, 22, 63-70. [CrossRef]

15. Stocker, M.D.; Pachepsky, Y.A.; Hill, R.L.; Sellner, K.G.; Macarisin, D.; Staver, K.W. Intraseasonal variation of E. coli and environmental covariates in two irrigation ponds in Maryland, USA. Sci. Total Environ. 2019, 670, 732-740. [CrossRef] [PubMed]

16. Moses, W.J.; Gitelson, A.A.; Perk, R.L.; Gurlin, D.; Rundquist, D.C.; Leavitt, B.C.; Barrow, T.M.; Brakhage, P. Estimation of chlorophyll-a concentration in turbid productive waters using airborne hyperspectral data. Water Res. 2012, 46, 993-1004. [CrossRef] [PubMed]

17. Pyo, J.C.; Pachepsky, Y.; Baek, S.S.; Kwon, Y.S.; Kim, M.J.; Lee, H.; Park, S.; Cha, Y.K.; Ha, R.; Nam, G.; et al. Optimizing semi-analytical algorithms for estimating chlorophyll-a and phycocyanin concentrations in inland waters in Korea. Remote Sens. 2017, 9, 542. [CrossRef]

18. Maier, P.M.; Keller, S. Estimating chlorophyll a concentrations of several inland waters with hyperspectral data and machine learning models. ISPRS Ann. Photogramm. Remote Sens. Spat. Inf. Sci. 2019, 4, 609-614. [CrossRef]

19. Blaustein, R.A.; Pachepsky, Y.; Hill, R.L.; Shelton, D.R.; Whelan, G. Escherichia coli survival in waters: Temperature dependence. Water Res. 2013, 47, 569-578. [CrossRef]

20. Pachepsky, Y.; Shelton, D.R.; McLain, J.E.T.; Patel, J.; Mandrell, R.E. Irrigation Waters as a Source of Pathogenic Microorganisms in Produce: A Review. Adv. Agron. 2011, 113, 75-141.

21. Havelaar, A.H.; Vazquez, K.M.; Topalcengiz, Z.; Muñoz-Carpena, R.; Danyluk, M.D. Evaluating the U.S. Food Safety Modernization Act Produce Safety Rule Standard for Microbial Quality of Agricultural Water for Growing Produce. J. Food Prot. 2017, 80, 1832-1841. [CrossRef]

22. Chen, C.H.; Landgrebe, D. Information Extraction Principles and Methods for Multispectral and Hyperspectral Image Data. Inf. Process. Remote Sens. 1999, 3-37. [CrossRef]

23. Cloutis, E.A. Review article hyperspectral geological remote sensing: Evaluation of analytical techniques. Int. J. Remote Sens. 1996, 17, 2215-2242. [CrossRef]

24. Khan, M.J.; Khan, H.S.; Yousaf, A.; Khurshid, K.; Abbas, A. Modern Trends in Hyperspectral Image Analysis: A Review. IEEE Access 2018, 6, 14118-14129. [CrossRef] 
25. Adão, T.; Hruška, J.; Pádua, L.; Bessa, J.; Peres, E.; Morais, R.; Sousa, J.J. Hyperspectral imaging: A review on UAV-based sensors, data processing and applications for agriculture and forestry. Remote Sens. 2017, 9, 1110. [CrossRef]

26. Govender, M.; Chetty, K.; Bulcock, H. A review of hyperspectral remote sensing and its application in vegetation and water resource studies. Water SA 2007, 33, 145-151. [CrossRef]

27. Liew, S.C.; Choo, C.K.; Lau, J.W.M.; Chan, W.S.; Dang, T.C. Monitoring water quality in Singapore reservoirs with hyperspectral remote sensing technology. Water Pract. Technol. 2019, 14, 118-125. [CrossRef]

28. Wang, Z.; Kawamura, K.; Sakuno, Y.; Fan, X.; Gong, Z.; Lim, J. Retrieval of chlorophyll-a and total suspended solids using iterative stepwise elimination partial least squares (ISE-PLS) regression based on field hyperspectral measurements in irrigation ponds in Higashihiroshima, Japan. Remote Sens. 2017, 9, 264. [CrossRef]

29. Abdel-Rahman, E.M.; Mutanga, O.; Odindi, J.; Adam, E.; Odindo, A.; Ismail, R. Estimating Swiss chard foliar macro- and micronutrient concentrations under different irrigation water sources using ground-based hyperspectral data and four partial least squares (PLS)-based (PLS1, PLS2, SPLS1 and SPLS2) regression algorithms. Comput. Electron. Agric. 2017, 132, 21-33. [CrossRef]

30. Gitelson, A.A.; Dall'Olmo, G.; Moses, W.; Rundquist, D.C.; Barrow, T.; Fisher, T.R.; Gurlin, D.; Holz, J. A simple semi-analytical model for remote estimation of chlorophyll-a in turbid waters: Validation. Remote Sens. Environ. 2008, 112, 3582-3593. [CrossRef]

31. Dall'Olmo, G.; Gitelson, A.A. Erratum: Effect of bio-optical parameter variability on the remote estimation of chlorophyll-a concentration in turbid productive waters: Experimental results. Appl. Opt. 2005, 44, 3342. [CrossRef]

32. Blaustein, J. The peak near $700 \mathrm{~nm}$ on radiance spectra of algae and water: Relationships of its magnitude and position with chlorophyll. Int. J. Remote Sens. 1992, 13, 3367-3373.

33. Randolph, K.; Wilson, J.; Tedesco, L.; Li, L.; Pascual, D.L.; Soyeux, E. Hyperspectral remote sensing of cyanobacteria in turbid productive water using optically active pigments, chlorophyll a and phycocyanin. Remote Sens. Environ. 2008, 112, 4009-4019. [CrossRef]

34. Pachepsky, Y.; Kierzewski, R.; Stocker, M.; Sellner, K.; Mulbry, W.; Lee, H.; Kim, M. Temporal stability of Escherichia coli concentrations in waters of two irrigation ponds in Maryland. Appl. Environ. Microbiol. 2018, 84, 1-12.

35. Kim, M.S.; Chao, K.; Chan, D.E.; Jun, W.; Lefcourt, A.M.; Delwiche, S.R.; Kang, S.; Lee, K. Line-Scan Hyperspectral Imaging Platform for Agro-Food Safety and Quality Evaluation: System Enhancement and Characterization. Trans. ASABE 2011, 54, 703-711. [CrossRef]

36. Qin, J.; Chao, K.; Kim, M.S.; Lu, R.; Burks, T.F. Hyperspectral and multispectral imaging for evaluating food safety and quality. J. Food Eng. 2013, 118, 157-171. [CrossRef]

37. Kim, M.S.; Chen, Y.R.; Mehl, P.M. Hyperspectral reflectance and fluorescence imaging system for food quality and safety. Trans. Am. Soc. Agric. Eng. 2001, 44, 721-729.

38. Baek, I.; Kim, M.S.; Cho, B.K.; Mo, C.; Barnaby, J.Y.; McClung, A.M.; Oh, M. Selection of optimal hyperspectral wavebands for detection of discolored, diseased rice seeds. Appl. Sci. 2019, 9, 1027. [CrossRef]

39. Flores-de-Santiago, F.; Kovacs, J.M.; Flores-Verdugo, F. The influence of seasonality in estimating mangrove leaf chlorophyll-a content from hyperspectral data. Wetl. Ecol. Manag. 2013, 21, 193-207. [CrossRef]

40. Ji-Yong, S.; Xiao-Bo, Z.; Jie-Wen, Z.; Kai-Liang, W.; Zheng-Wei, C.; Xiao-Wei, H.; De-Tao, Z.; Holmes, M. Nondestructive diagnostics of nitrogen deficiency by cucumber leaf chlorophyll distribution map based on near infrared hyperspectral imaging. Sci. Hortic. (Amsterdam). 2012, 138, 190-197. [CrossRef]

41. Zhang, H.; Zhu, L.F.; Hu, H.; Zheng, K.F.; Jin, Q.Y. Monitoring leaf chlorophyll fluorescence with spectral reflectance in Rice (Oryza sativa L.). Procedia Eng. 2011, 15, 4403-4408. [CrossRef]

42. Luoheng, H.; Rundquist, D.C. Comparison of NIR/RED ratio and first derivative of reflectance in estimating algal-chlorophyll concentration: A case study in a turbid reservoir. Remote Sens. Environ. 1997, 62, 253-261.

43. Gons, H.J. Optical teledetection of chlorophyll a in turbid inland waters. Environ. Sci. Technol. 1999, 33, 1127-1132. [CrossRef]

44. Cho, B.K.; Kim, M.S.; Baek, I.S.; Kim, D.Y.; Lee, W.H.; Kim, J.; Bae, H.; Kim, Y.S. Detection of cuticle defects on cherry tomatoes using hyperspectral fluorescence imagery. Postharvest Biol. Technol. 2013, 76, 40-49. [CrossRef]

45. Manley, M. Near-infrared spectroscopy and hyperspectral imaging: Non-destructive analysis of biological materials. Chem. Soc. Rev. 2014, 43, 8200-8214. [CrossRef] 
46. Xu, M.; Liu, H.; Beck, R.; Lekki, J.; Yang, B.; Shu, S.; Liu, Y.; Benko, T.; Anderson, R.; Tokars, R.; et al. Regionally and Locally Adaptive Models for Retrieving Chlorophyll-a Concentration in Inland Waters from Remotely Sensed Multispectral and Hyperspectral Imagery. IEEE Trans. Geosci. Remote Sens. 2019, 57, 4758-4774. [CrossRef]

47. Giardino, C.; Bresciani, M.; Valentini, E.; Gasperini, L.; Bolpagni, R.; Brando, V.E. Airborne hyperspectral data to assess suspended particulate matter and aquatic vegetation in a shallow and turbid lake. Remote Sens. Environ. 2015, 157, 48-57. [CrossRef]

(C) 2020 by the authors. Licensee MDPI, Basel, Switzerland. This article is an open access article distributed under the terms and conditions of the Creative Commons Attribution (CC BY) license (http://creativecommons.org/licenses/by/4.0/). 